\title{
Reabilitação protética de paciente oncológico: relato de caso
}

\author{
Prosthetic rehabilitation of oncological patient: case report \\ Rehabilitación protésica de paciente oncologico: presentación de un caso
}

\author{
Alex Junqueira ESTEVES ${ }^{1}$ \\ Fernanda Correa de Morais COSTA \\ Marcela Filié HADDAD ${ }^{2}$ \\ ${ }^{1}$ Graduação em Odontologia, Departamento de Odontologia Restauradora, Faculdade de Odontologia de Alfenas, \\ Universidade Federal de Alfenas, UNIFAL, 37.130-000 Alfenas-MG, Brasil \\ ${ }^{2}$ Cirurgiã-Dentista, Mestre e Doutora em Prótese Dentária, Professora da Disciplina de Prótese Parcial Removível, \\ Departamento de Odontologia Restauradora, Faculdade de Odontologia de Alfenas, Universidade Federal de Alfenas, \\ UNIFAL, Alfenas-MG, Brasil
}

\begin{abstract}
Resumo
O câncer de boca é um dos tipos de neoplasia mais frequentes na população, podendo ter várias etiologias e diversos tratamentos, que muitas vezes resultam na mutilação de seu portador. Assim, o objetivo desse trabalho é relatar um caso de reabilitação protética de paciente oncológico por meio de prótese obturadora após ressecção de tumor em região anterior de maxila e uso temporário de sonda nasogástrica. Todos os procedimentos clínicos relacionados à construção de uma prótese total foram feitos baseando-se na literatura pesquisada, de forma a tornar o tratamento o mais reabilitador e menos traumático possível, resultando numa melhora substancial da saúde do paciente. Uma semana após a instalação, a prótese obturadora foi reembasada com Coe-soft (GC América, Alsip, IL, EUA) a fim de melhorar o vedamento da comunicação bucosinusal, aumentando, assim, sua retenção e estabilidade.
\end{abstract}

Descritores: Neoplasias Bucais; Reabilitação Bucal; Obturadores Palatinos; Neoplasias Maxilomandibulares.

\begin{abstract}
The oral cancer is one of the most frequent neoplasia it has diverse etiology and treatments, those treatments may lead to mutilation of the patient. The present work aims to present a clinic case of rehabilitation using obturator prosthesis. This particular patient needed to be rehabilitated after surgical removal of a tumour on the maxilar anterior portion, and temporary usage of nasogastric probe. The clinical procedures of impression taking, confection, testing and adaptation of the prosthetic guides, choosing teeth and gums, base adjustments, occlusal adjustments and prosthesis insertion were made basing on the literature review. Intending to do a rehabilitation treatment with minimum possible trauma, resulting in a substantial improvement of the patient health. After a week of adaptation the prosthesis was relined to provide better sealing between mouth and maxillary sinus increasing its retention and stability.
\end{abstract}

Descriptors: Mouth Neoplasms; Mouth Rehabilitation; Palatal Obturators; Jaw Neoplasms.

\section{Resumen}

Cáncer de boca es uno de los tipos más comunes de cáncer en la población, que pueden tener diferentes etiologías y tratamientos diferentes, que a menudo resulta en un daño a su portador. Por lo tanto, el objetivo de este trabajo es presentar un caso de rehabilitación protésica de pacientes con cáncer a través de la prótesis obturador. El paciente en cuestión tuvo que ser rehabilitado después de la resección del tumor en la parte anterior del maxilar y de uso temporal de una sonda nasogástrica. Todo clínica procedimientos de moldeo, fabricación, pruebas y adaptaciones de bases tales planos de orientación, la elección de los dientes y el ajuste de base de goma, ajuste oclusal y la instalación se realiza con base en la literatura, con el fin de hacer el tratamiento más de rehabilitación, y menos traumática posible, lo que resulta en una mejora sustancial en la salud del paciente. Una semana después de la instalación, la prótesis obturador era reembasada para mejorar el sellado de la comunicación bucosinusal, aumentando así la retención y estabilidad.

Descriptores: Neoplasias de la Boca; Reabilitación Bucal; Obturadores Palatinos; Neoplasias Maxilomandibulares.

\section{INTRODUÇÃO}

O Ministério da Saúde, por meio do Instituto Nacional de Câncer (INCA) ${ }^{1}$, estima que no ano de 2016 ocorram 15.490 novos casos de câncer de boca, sendo 11.140 em homens e 4.350 em mulheres.

Uma inspeção detalhada da cavidade oral permite a descoberta ou não de lesões e ulcerações que podem caracterizar o Câncer de Boca. Mas a população não tem informações acerca da forma de fazê-la ou quando procurar um profissional para um exame clínico ${ }^{3}$. Ainda, segundo Souza et al. ${ }^{3}$ em entrevistas nota-se que boa parte da população não vai regularmente ao dentista, apenas em caso de dor, o que pode favorecer o desenvolvimento e crescimento de uma lesão cancerosa por não ter sido diagnosticada anteriormente. 
A falta de conhecimento prejudica muito a avaliação correta para uma intervenção imediata. O diagnóstico precoce do câncer, na maioria dos casos, permite a resolução do quadro com apenas uma das várias terapias, que incluem cirurgia, radioterapia, quimioterapia e imunoterapia ${ }^{4}$. Porém, quando o diagnóstico é tardio, normalmente necessita da combinação das terapias apresentadas acima e também resulta em perdas teciduais extensas, que acabam por afetar a qualidade de vida do paciente. Quando a remoção da lesão implicar em grandes perdas de estrutura, o ideal é regenerar os tecidos perdidos por meio cirúrgico ${ }^{5}$.

Nestas situações, a reabilitação protética se faz necessária, pois promove um vedamento da cavidade bucal, minimizando a passagem de ar, líquido e alimento da boca para o nariz, auxiliando desta forma na alimentação e fonação do paciente. Os obturadores maxilares são alternativas que podem ser utilizadas nesses casos e consistem em discos que permitem reparar o defeito maxilar, contribuindo para a reabilitação funcional e estética do indivíduo mutilado, bem como para a devolução da sua autoestima. Porém, o tratamento com próteses obturadoras é complexo, pois os tecidos sobre os quais ela se apoia são delicados, muitas vezes a salivação é reduzida como resultado do tratamento radioterápico, o que dificulta a retenção da prótese e facilita a ocorrência de ferimentos na mucosa do paciente, decorrentes do atrito entre prótese e mucosa, gerado durante a função. Dependendo da extensão da comunicação e da quantidade de estruturas anatômicas restantes para apoiar a prótese, a retenção e a estabilidade da mesma ficam muito comprometidas. Estes fatores, aliados a falta de conhecimento específico (visto que este tipo de reabilitação não é comumente ensinado em cursos de graduação devido a sua dificuldade de execução) fazem com que muitos clínicos evitem realizar este tipo de tratamento em suas clínicas ${ }^{5-7}$.

O presente trabalho tem como objetivo relatar um caso clínico de reabilitação com prótese obturadora palatina, visando auxiliar o cirurgião-dentista clínico geral que pretende executar este tipo de procedimento.

\section{CASO CÍNICO}

O caso clínico em questão trata da reabilitação protética de um paciente que passou por tratamento oncológico, levando a ressecção de parte da maxila e necessitando, assim, de reabilitação por meio de prótese obturadora palatina e prótese total inferior.

O paciente V.T.V, sexo masculino, leucoderma, 80 anos, procurou atendimento na clínica de Cirurgia da UNIFAL-MG queixando-se de dor na região anterior da maxila. Ao exame clínico intraoral notou-se mobilidade acentuada dos elementos 11 e 22 e a existência de uma lesão de aspecto granuloso, localização intraóssea, consistência flácida e coloração avermelhada (Figura 1).

Frente ao quadro observado durante o exame clínico intraoral, se fez necessária a tomada de uma radiografia panorâmica de boca semi aberta para avaliação da área comprometida. Notou-se área de rarefação óssea bem definida na região anterior direita de maxila, indicada por uma extensa área radiolúcida bem circunscrita. Assim, optouse pela extração dos elementos envolvidos, biópsia incisional da lesão e curetagem do material para análise histopatológica (Figuras 2A, 2B e 2C).

$\mathrm{O}$ exame histopatológico apontou a presença de fragmentos de tecido epitelial do tipo pavimentoso, estratificado, apresentando hiperqueratose, acantose, displasia e intensa hiperplasia verrucosa, além de exocitose e degeneração hidrópica. A camada basal do epitélio encontrava-se intensamente proliferativa, além de apresentar exocitose e células pleomórficas, hipercromáticas e mitoses. A escassa lâmina própria subjacente encontrava-se permeada por intenso infiltrado inflamatório mononuclear. Áreas hemorrágicas e focos basofílicos cementóides completavam o quadro. Com esta descrição, o laudo sugeria acompanhamento clínico e repetição da biópsia.

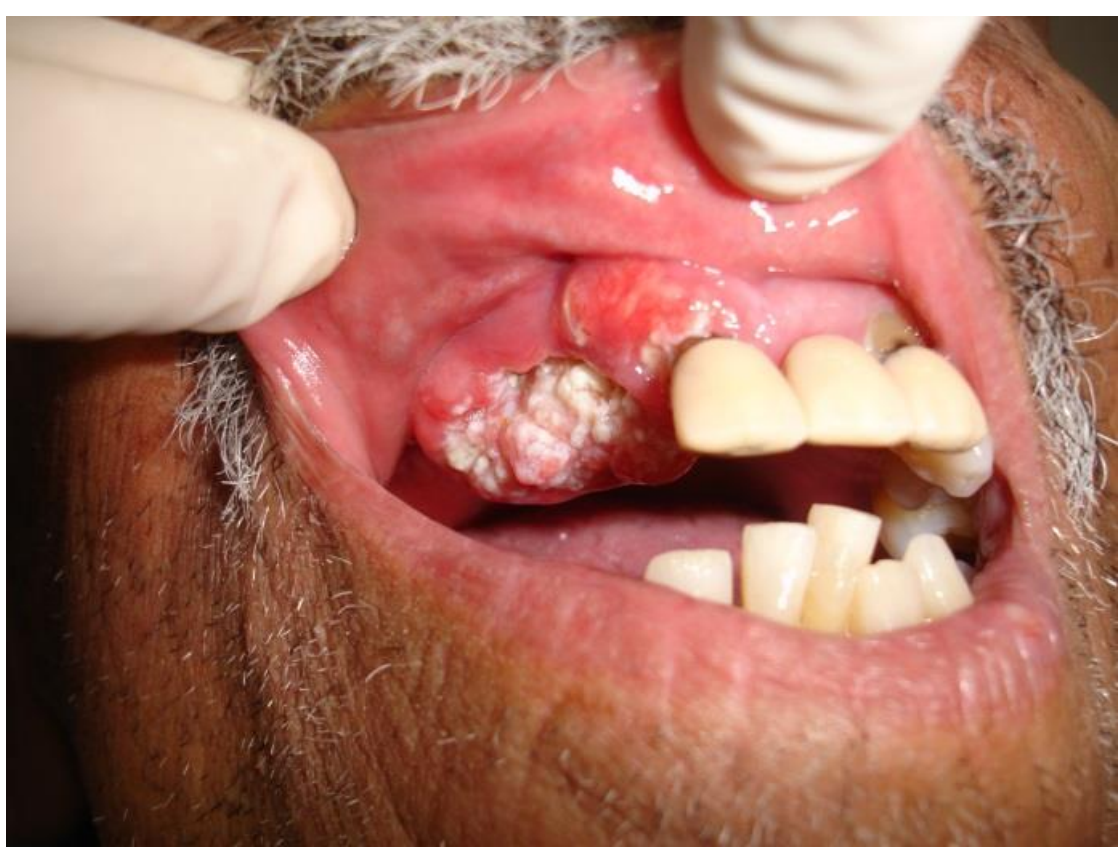

Figura 1: Aspecto inicial da lesão.

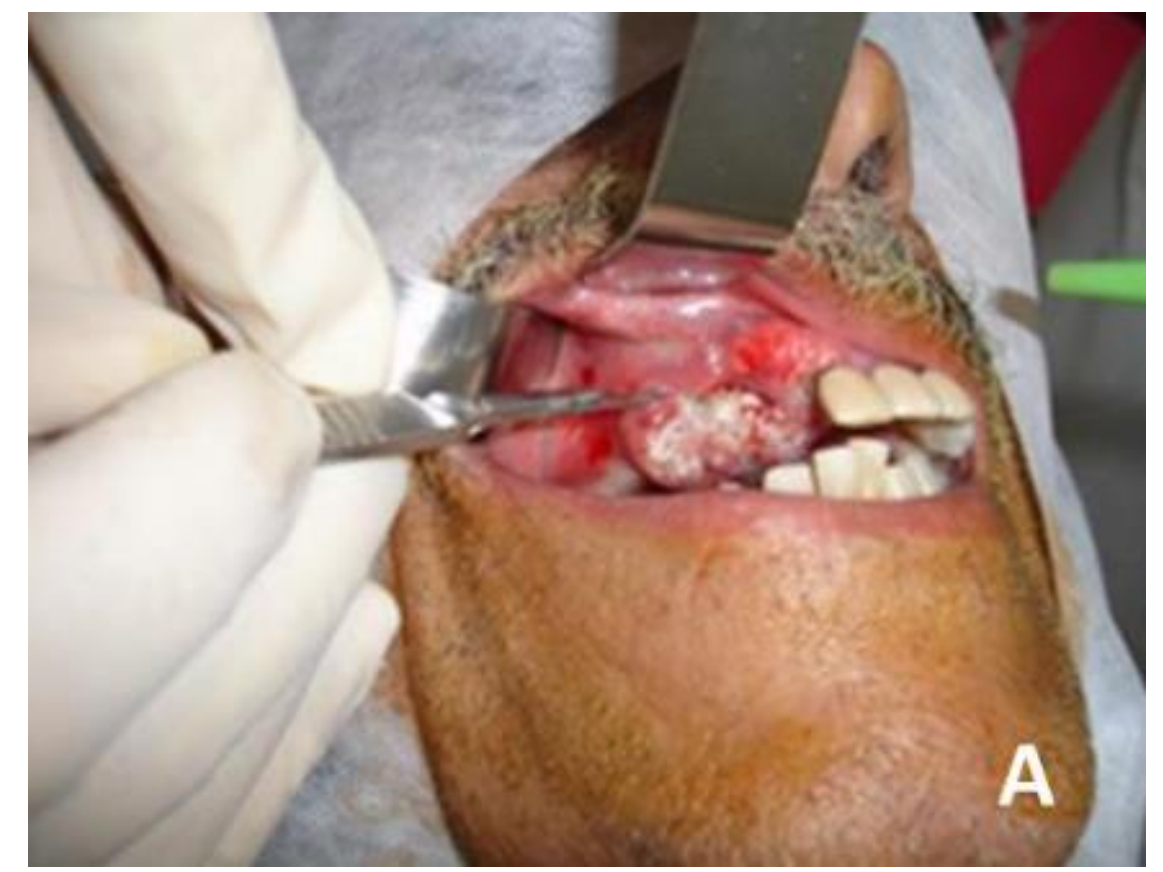

Figura 2A: Incisão para remoção da lesão.

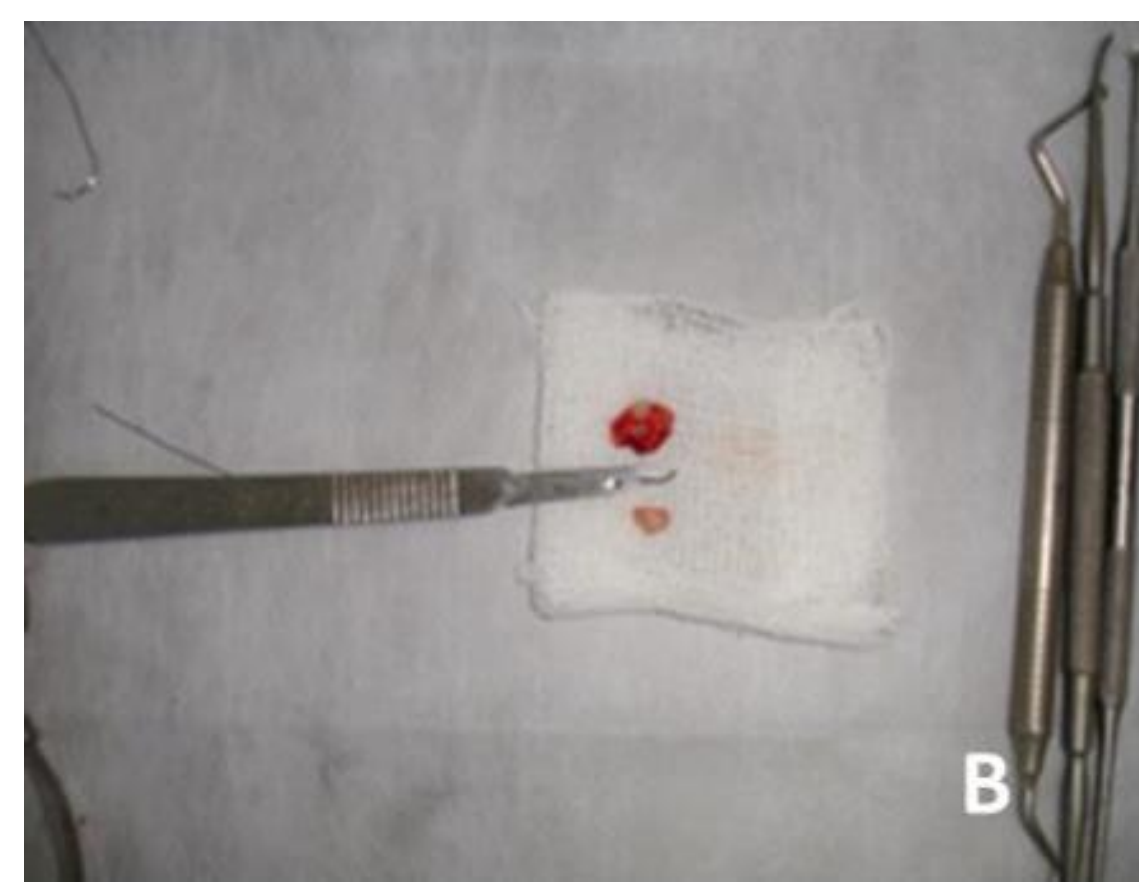

Figura 2B: Fragmento da lesão a ser enviada para análise histopatológica. 


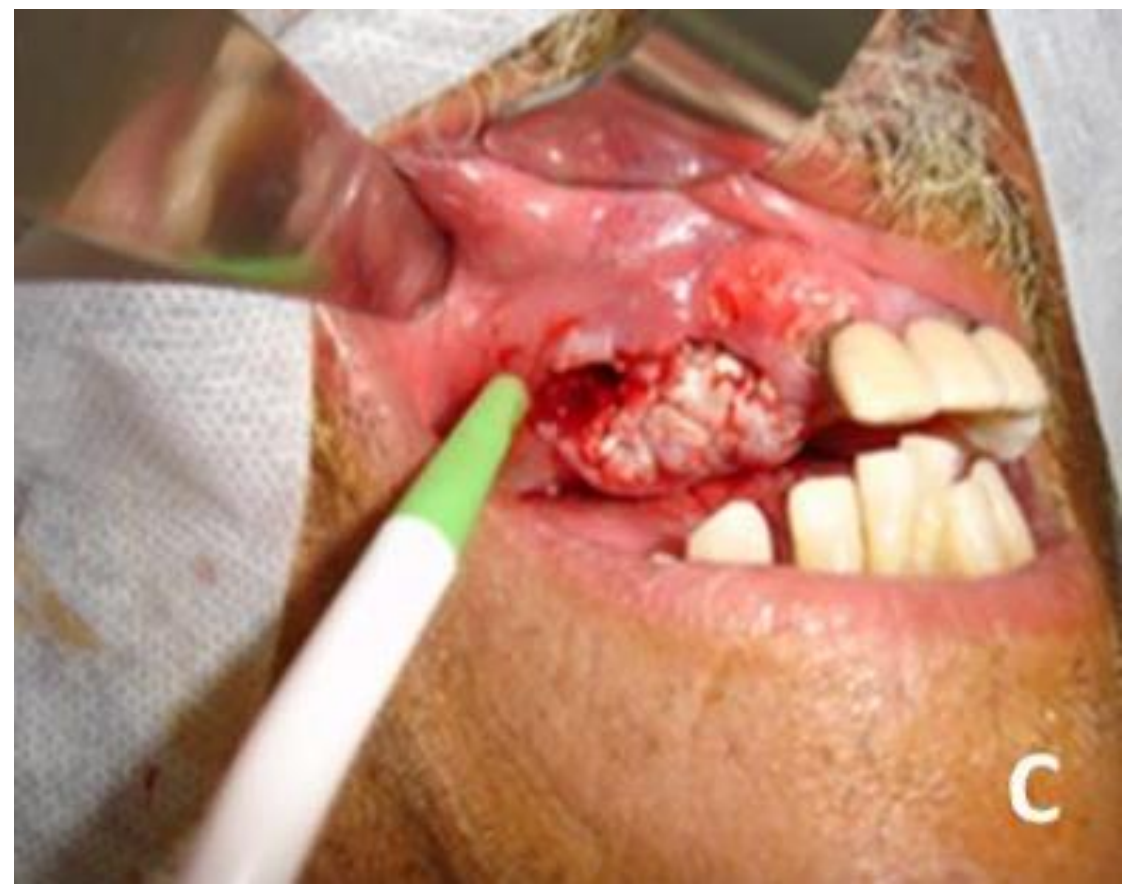

Figura 2C: Aspecto clínico pós-biópsia.

Desta maneira, o paciente foi encaminhado para atendimento na clínica de Estomatologia da UNIFAL-MG, para a realização de nova biópsia e exame histopatológico. A partir desta nova cirurgia foi emitido o laudo de carcinoma espinocelular de lesão em maxila e o paciente foi encaminhado para tratamento oncológico na Santa Casa de Alfenas, onde foi submetido à maxilectomia parcial (Figura 3) e instalação de sonda nasogástrica para permitir a nutrição do mesmo, uma vez que a deglutição estava comprometida devido à comunicação buconasal gerada.

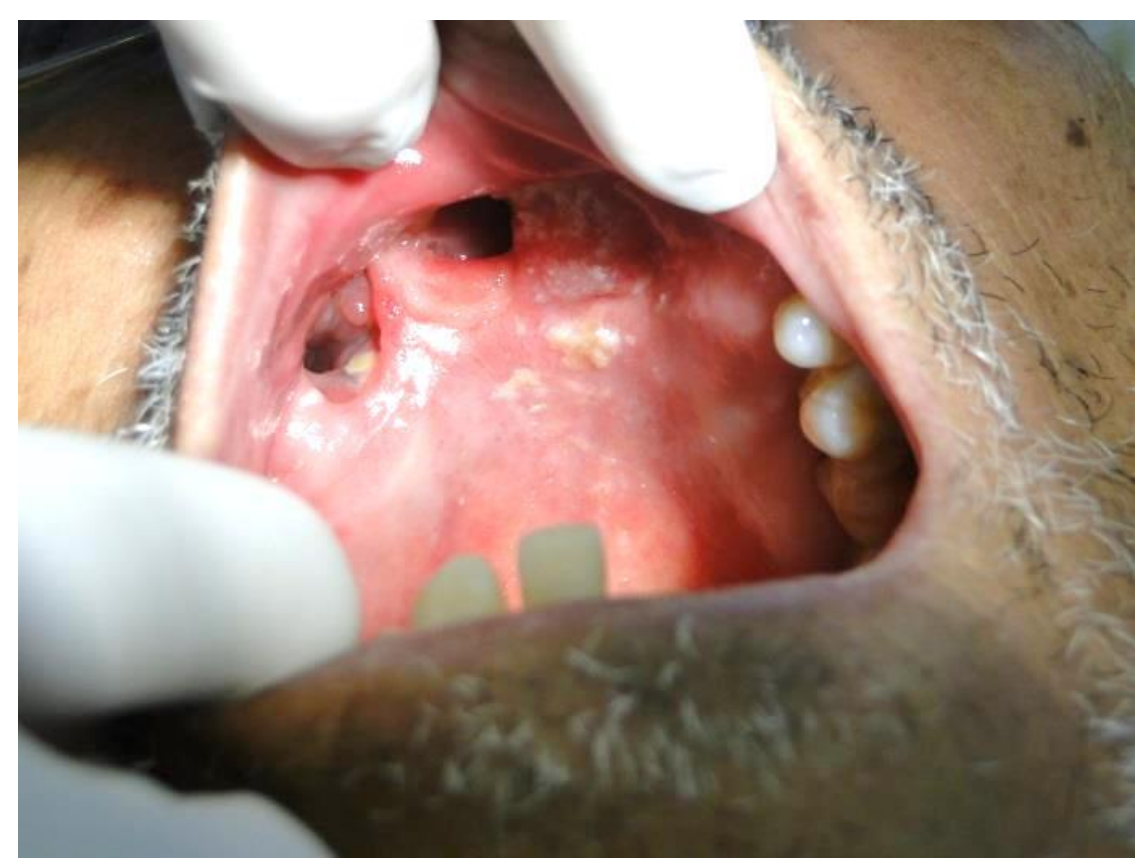

Figura 3: Aspecto clínico após a maxilectomia parcial.

Vinte dias após a instalação da sonda o paciente procurou atendimento na clínica de Prótese da UNIFAL-MG, sob orientação médica, para a confecção de um obturador palatino provisório retido aos dentes remanescentes para que a sonda pudesse ser removida e o paciente, que havia perdido 12 quilos neste período, pudesse voltar a se alimentar por via oral. Para isso, um obturador palatino confeccionado com Resina Acrílica Ativada Termicamente (RAAT) e retido aos dentes remanescentes por meio de grampos ortodônticos foi instalado (Figura 4).

Durante acompanhamento médico foi considerada a possibilidade da realização de tratamento radioterápico. Para tal, o oncologista solicitou análise dos dentes inferiores remanescentes para avaliação da necessidade de extração previamente à radioterapia. As extrações eram indicadas e, portanto, foram realizadas. Neste primeiro momento, os dentes superiores ainda foram preservados, pois seriam extremamente importantes para a retenção e estabilização da futura prótese obturadora palatina.

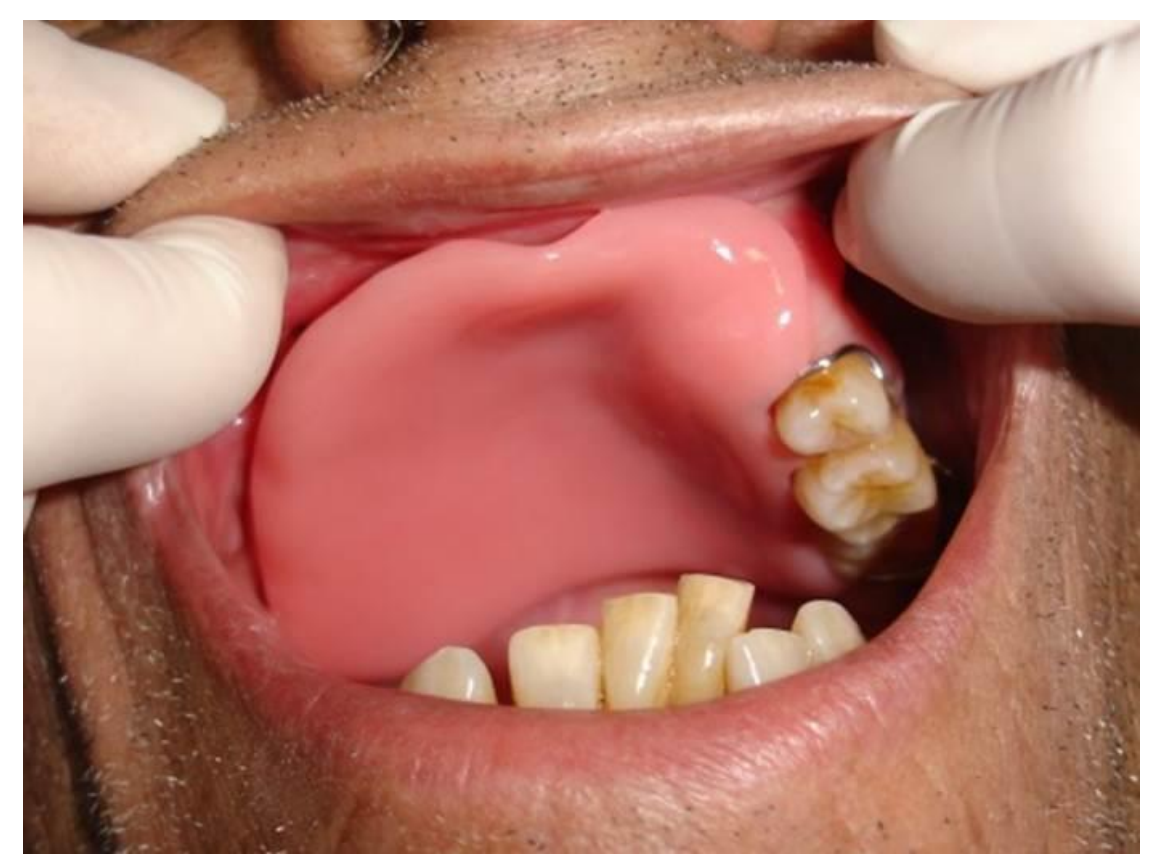

Figura 4: Obturador palatino provisório instalado.

O médico solicitou que as próteses fossem instaladas previamente ao início da radioterapia a fim de melhorar a nutrição do paciente, o que seria necessário para fortalecer seu estado imunológico. Dessa maneira, o planejamento protético incluía, neste momento, a confecção de uma Prótese Parcial Removível Obturadora Palatina provisória, retida por meio de grampos ortodônticos devido a falta de destreza do paciente para inserir e remover uma prótese confeccionada com grampos fundidos; e uma Prótese Total Removível mandibular convencional.

Tanto a prótese obturadora quanto a prótese convencional foram executadas seguindo o protocolo estabelecido por Rezende et al. ${ }^{8}$, compreendendo os seguintes passos clínicos:

1- Moldagem de estudo:

MAXILA: A área da comunicação buconasal foi protegida com uma gaze embebida com soro fisiológico para evitar a entrada de excesso de material de moldagem no defeito. Em seguida, foi selecionado o par de moldeiras de estoque para a execução da moldagem. As mesmas não tiveram suas bordas individualizadas com cera periférica devido à falta de espaço oriunda da maxilectomia e sutura dos tecidos remanescentes, perdendo o limite de fundo de saco na região do defeito bem como a limitação de abertura bucal que o paciente apresentava nesta fase. $\mathrm{O}$ material de escolha para moldagem de estudo dos dois arcos foi o alginato. Este material foi proporcionado e manipulado seguindo as instruções do fabricante; inserido no interior das moldeiras, que foram levadas à boca e aguardada a geleificação do material para a remoção dos moldes da boca. Em seguida, foi checada a qualidade da impressão e obtidos os modelos de estudo.

MANDÍBULA: Foi realizada moldagem com moldeira de estoque para pacientes desdentados totais, perfurada, com bordas individualizadas com cera periférica e utilizando alginato, da mesma maneira como descrito previamente.

2- Obtenção de modelos de estudo: A partir destes moldes foram obtidos modelos de estudo vazados em gesso comum. Sobre o modelo maxilar foi confeccionada base de prova em Resina Acrílica Ativada Quimicamente (RAAQ) e rolete de cera. Já sobre o modelo mandibular foi confeccionada moldeira individual, também com RAAQ.

3- Moldagem funcional: A moldagem funcional do arco mandibular foi executada utilizando moldeira individual e o conjunto de silicone de condensação (silicone pesado para 
moldagem de bordas e silicone leve para a moldagem de rebordos). A partir deste novo molde, foram obtidos os modelos de trabalho, sobre o qual também foi confeccionada base de prova e rolete de cera para a tomada de registros intermaxilares que permitiram a montagem dos modelos em articulador.

4- Tomada de registros intermaxilares e montagem dos modelos em articulador semi-ajustável: Inicialmente, o plano de cera superior foi inserido na boca do paciente e ajustado quanto ao seu volume vestibular, altura e inclinação. Foram marcadas as linhas para seleção e posicionamento dos dentes artificiais. Em seguida, com o auxílio do arco facial, o plano de cera superior foi transferido para $o$ articulador semiajustável. Nesta etapa o paciente precisou interromper o tratamento reabilitador protético para dar início à radioterapia. Apesar da avaliação odontológica sugerir a manutenção dos dentes remanescentes superiores, antes de iniciar o tratamento radioterápico o médico nos encaminhou o paciente mais uma vez solicitando a extração destes elementos.

Os dentes maxilares foram extraídos, mudando o planejamento protético pré-estabelecido, pois agora o paciente passava do quadro de desdentado parcial maxilar para desdentado total, apresentando um arco com comunicação buconasal e ausência de limites precisos de fundo de sulco, o que dificultaria sobremaneira e retenção e estabilidade da prótese obturadora.

O paciente passou por todo tratamento radioterápico e retornou para que as próteses fossem finalizadas.

Como os dentes maxilares foram extraídos, foi solicitado ao técnico em prótese que fizesse a extração dos dentes no modelo maxilar que já estava montado em articulador, e que recobrisse esta região com resina acrílica, completando o rolete de cera, transformando, assim, em uma base de prova para paciente desdentado total.

$\mathrm{O}$ passo seguinte consistiu no ajuste do rolete de cera inferior para determinação da dimensão vertical de repouso e de oclusão. Feitos os ajustes necessários, os dois roletes foram levados à boca do paciente, que teve sua mandíbula guiada para a posição de relação central, a qual foi registrada unindo-se os dois roletes por meio de grampos. Os roletes foram removidos da boca do paciente e posicionados sobre o modelo maxilar, já montado em articulador, para a montagem do modelo mandibular.

5- Seleção dos dentes artificiais: A cor, o formato e o tamanho dos dentes foram selecionados a partir do tom de pele, características físicas, formato do rosto do paciente e das medidas marcadas no rolete de cera. Em seguida, o articulador foi enviado ao laboratório para a montagem dos dentes artificiais.

6- Prova estética e funcional: Nesta etapa, as próteses com os dentes montados em cera foram provadas no paciente e foi analisada sua estética (confirmando se a cor, formato e tamanho dos dentes estavam satisfatórios e se o suporte labial estava adequado) e também a função (observando se a estabilidade da prótese e a pronúncia do paciente estavam adequadas).

Devido à pobre estabilidade decorrente da adaptação da base na região onde foram feitas as extrações no modelo e também à grande passagem de ar pela comunicação buconasal durante a fala, foi notada a necessidade de uma moldagem corretiva. Para esta moldagem, foi selecionada a técnica da boca fechada. Inicialmente foi realizado ajuste oclusal em abertura e fechamento, desgastando-se pontos de contato oclusal mais fortes. Em seguida foi aplicado adesivo na superfície interna da base da prótese superior e aguardada sua secagem. A pasta leve e o catalisador da silicona foram proporcionados e manipulados seguindo as recomendações do fabricante, e então inserido na superfície interna da base da prótese. $\mathrm{O}$ conjunto foi levado à boca do paciente que foi orientado a ocluir em posição de relação central e manter nessa posição até a presa da silicona (Figuras 5A e 5B).

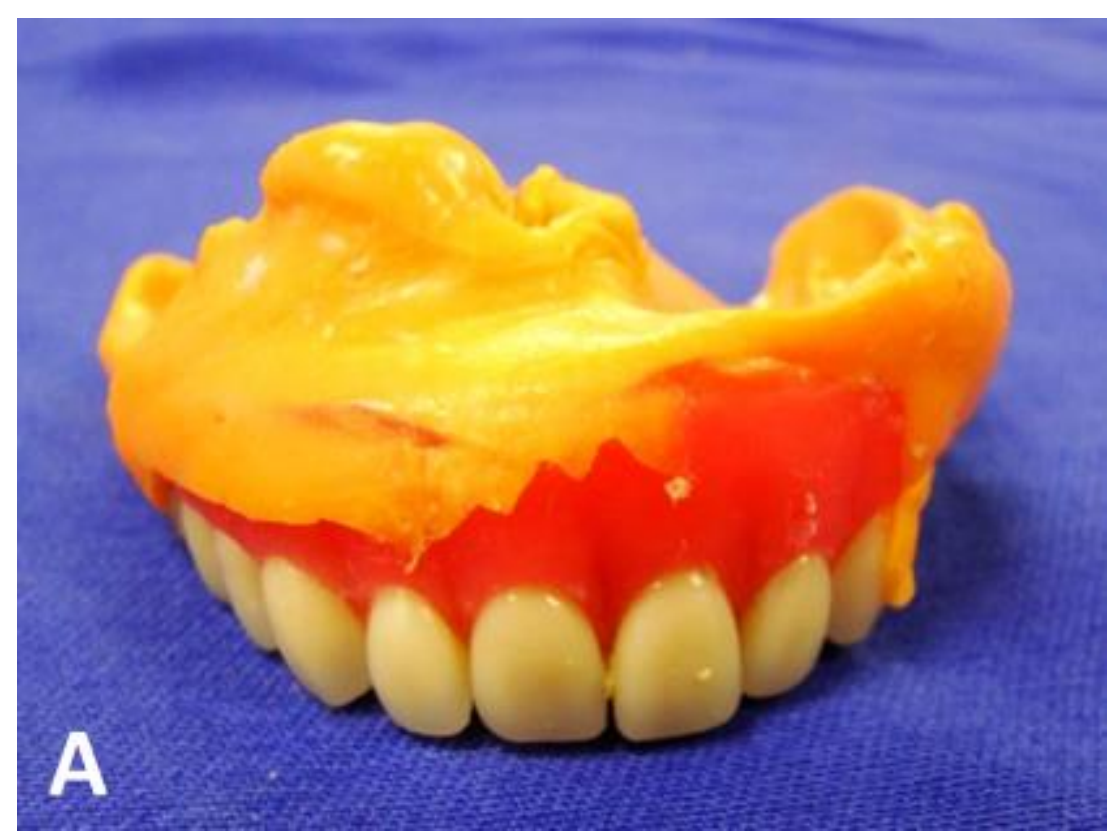

Figura 5A: Molde realizado a partir da técnica da boca fechada. Vista vestibular, possibilitando observar o aumento do bulbo obturador.

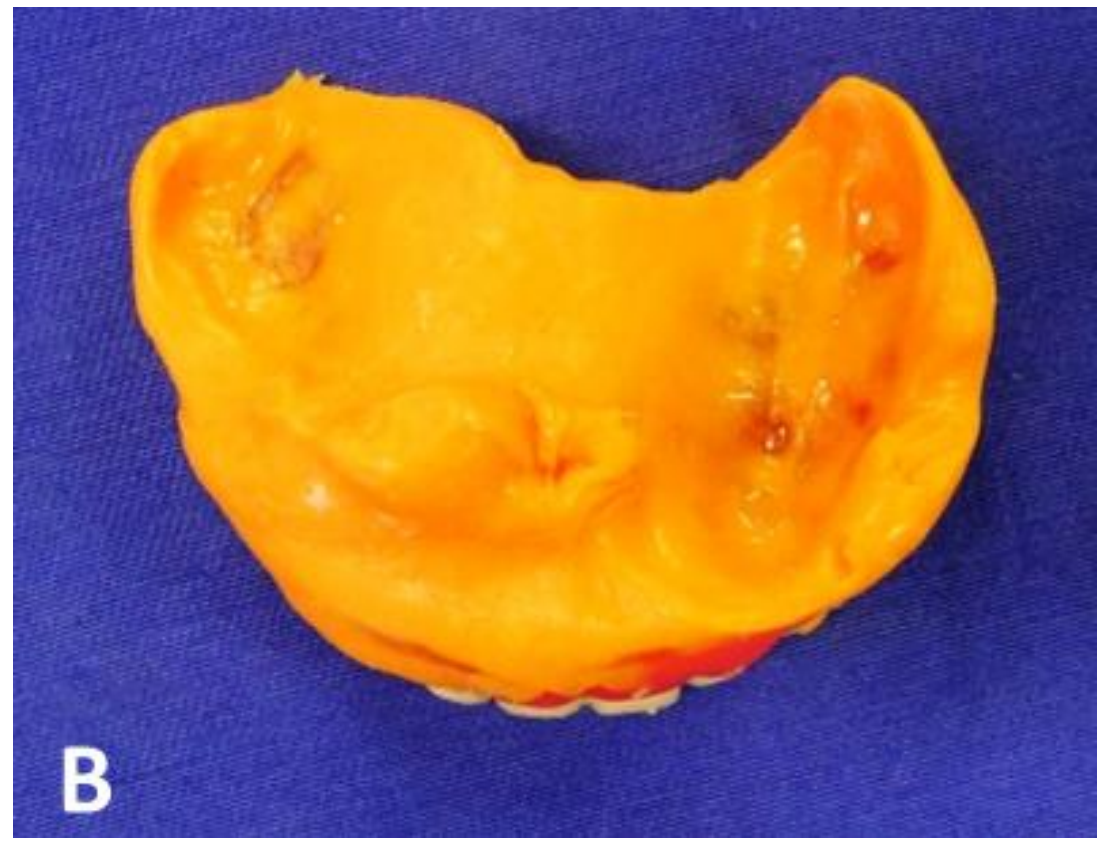

Figura 5B: Molde realizado a partir da técnica da boca fechada Preenchimento completo da base pelo material de moldagem, corrigindo a região posterior esquerda, que sofreu exodontias.

Feitas todas as adaptações necessárias, foi selecionada a cor escuro para as bases utilizando-se escala STG (Sistema Tomaz Gomes) de caracterização de resina acrílica e as próteses foram enviadas ao laboratório para acrilização.

7- Instalação das próteses: As próteses já acrilizadas e polidas (Figura 6) foram instaladas no paciente. Nesta etapa, foram realizados ajustes de bases com auxílio de pasta evidenciadora de contato (bisnaga base da pasta zincoenólica) e minicut. Também foi realizado ajuste oclusal após checagem de contato com fita de carbono durante a realização de movimentos de abertura e fechamento, lateralidade e protrusão mandibular.

O paciente recebeu orientações a respeito da forma de uso, higienização e importância dos retornos periódicos para avaliação e se necessário alguns ajustes.

8- Reembasamento: Uma semana após a instalação das próteses o paciente retornou se queixando que a prótese maxilar estava instável. A mesma foi reembasada com reembasador resiliente temporário (Coe-soft, GC América, 
Alsip, IL, EUA) a fim de aumentar ainda mais o bulbo obturador, vendando a cavidade de forma mais satisfatória e dando maior retenção e estabilidade a prótese obturadora maxilar.

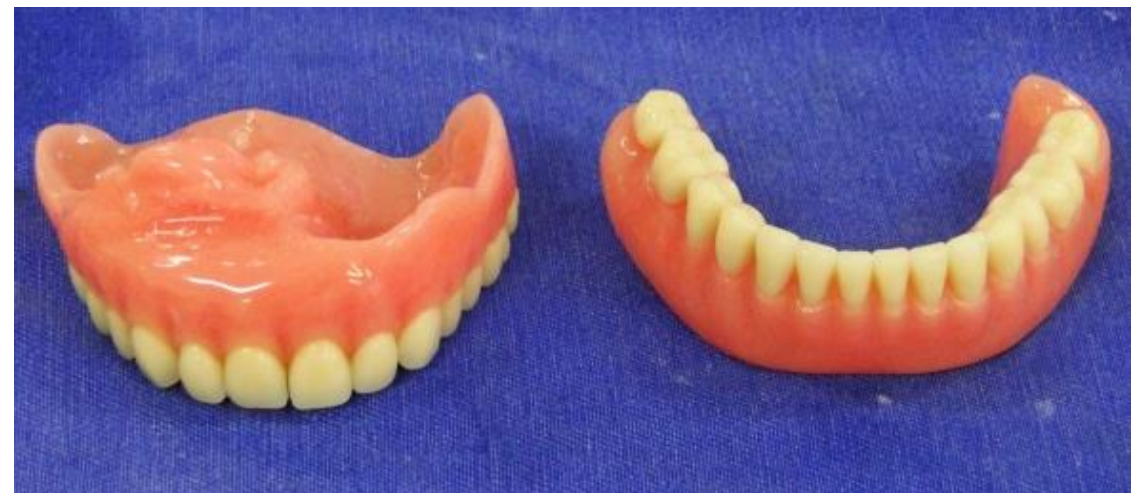

Figura 6: Prótese Obturadora Palatina e Prótese Total mandibular acrilizadas e polidas.

Inicialmente, a prótese obturadora foi limpa, o isolante que acompanha o kit de material reembasador foi aplicado na região vestibular da prótese e o material reembasador foi proporcionado e manipulado de acordo com as instruções do fabricante. Em seguida, o material foi aplicado na face interna da base, que foi levada a boca do paciente e estabilizada até a presa do material. Após a presa, a prótese foi removida da boca e os excessos de material recortados (Figuras 7A, 7B, 7C e 7D).

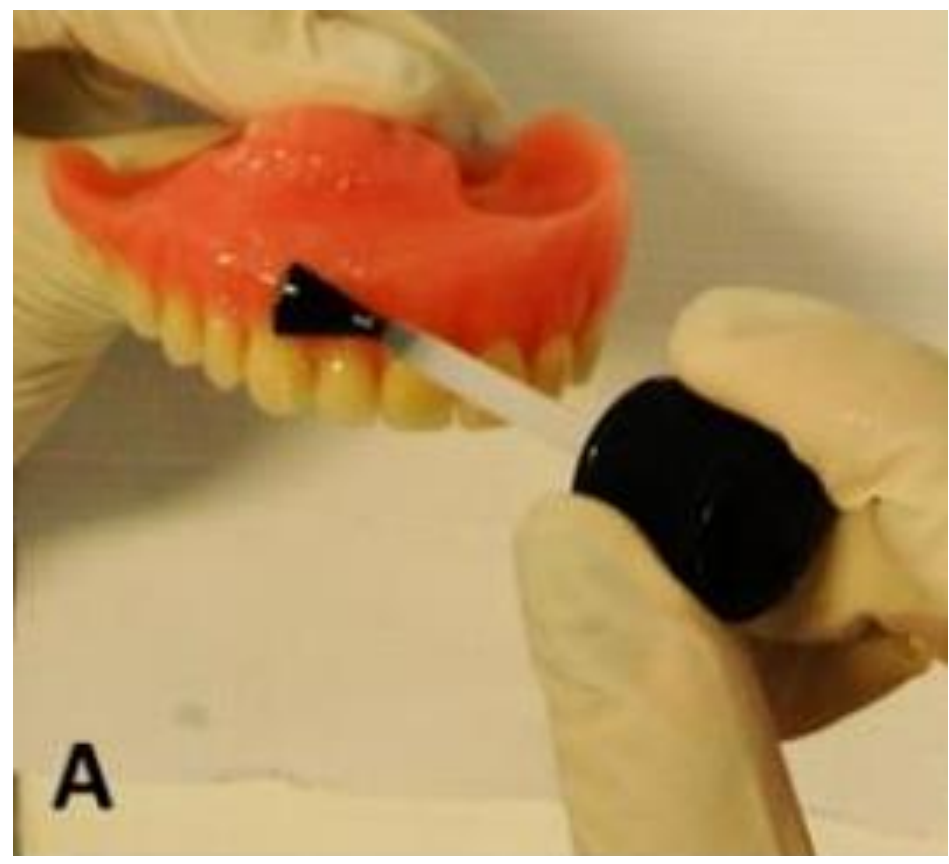

Figura 7A: Reembasamento da prótese obturadora palatina Aplicação do isolante na face vestibular da prótese.

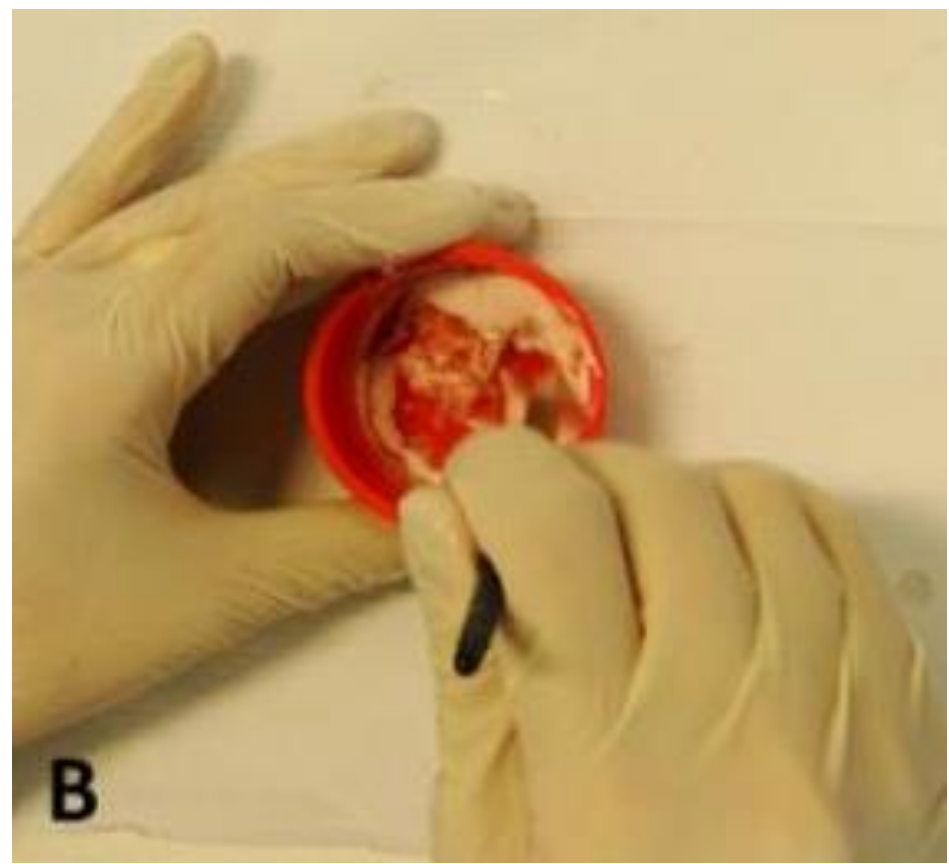

Figura 7B: Reembasamento da prótese obturadora palatina. Manipulação do material reembasador.

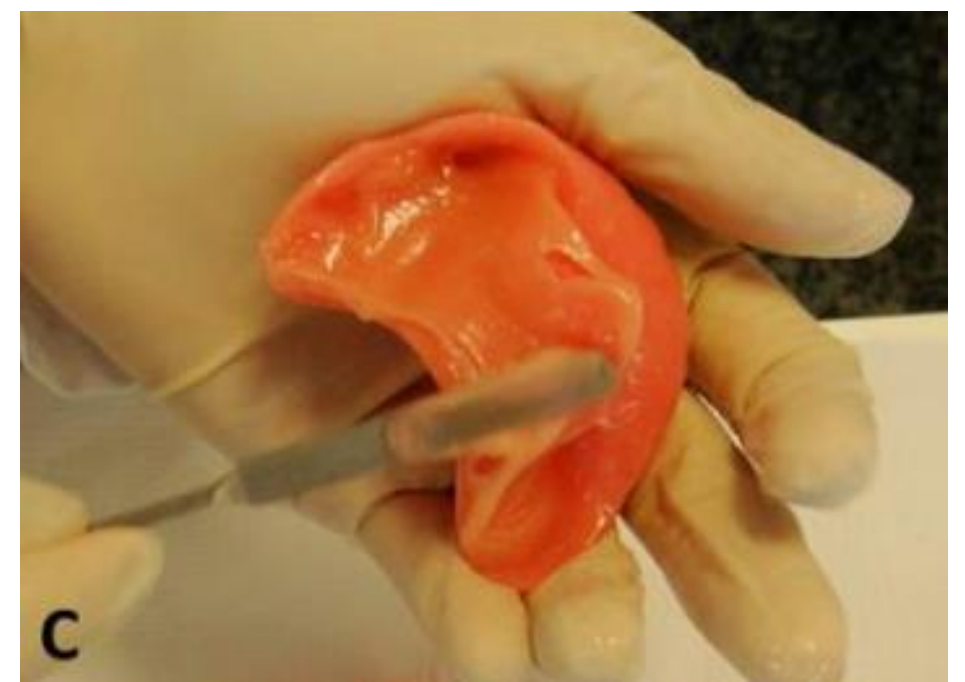

Figura 7C: Reembasamento da prótese obturadora palatina. Inserção do material na face interna da base.

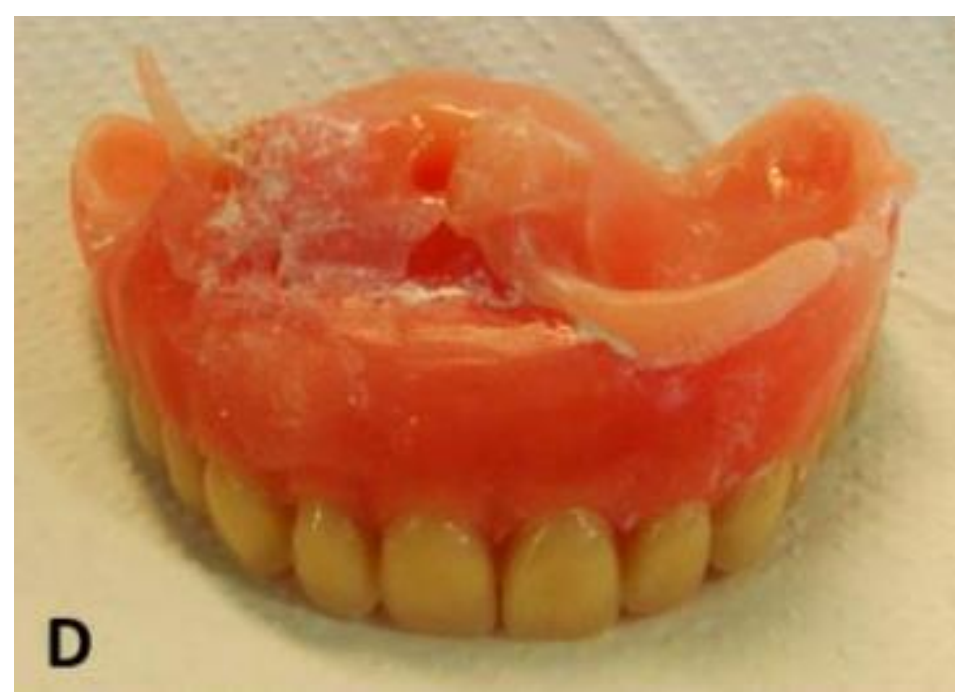

Figura 7D: Reembasamento da prótese obturadora palatina. Material reembasador após a polimerização.

Novo ajuste oclusal foi realizado e checada a retenção e estabilidade da prótese (Figura 8). O paciente foi orientado a retornar para substituição do material reembasador periodicamente.

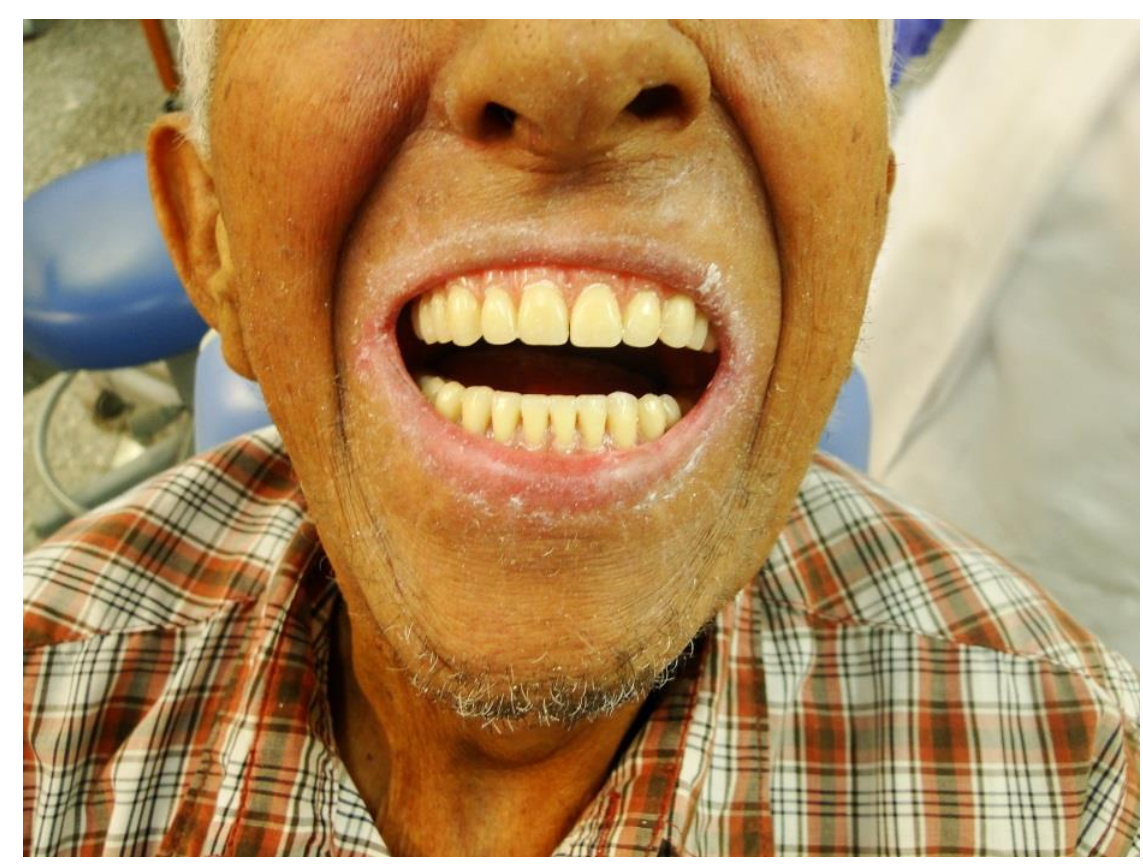

Figura 8: Aspecto final, após reembasamento e ajustes.

\section{DISCUSSÃO}

O paciente do caso em questão apresentava-se com lesão no rebordo alveolar com características clínicas indicativas de câncer, uma vez que, ao exame histopatológico, foram notadas características citadas por Margotta e Capogreco ${ }^{9}$ como: células anormais, mitoses frequentes, e núcleos volumosos com conteúdos anormais. Segundo Carli et al. ${ }^{10}$, um dos locais mais acometidos pelo câncer bucal é o rebordo alveolar, a maioria dos indivíduos 
acometidos são do sexo masculino. Indivíduos com idade superior a 71 anos possuem $34,8 \%$ de possibilidade de possuir a doença câncer ${ }^{11}$. Essas características são similares as do paciente reabilitado no presente relato.

O tratamento de eleição para tumores na maxila consiste na maxilectomia seguido por radioterapia, quando houver indicação ${ }^{12}$. Este foi $\mathrm{o}$ tratamento realizado no presente caso.

É consenso que após a maxilectomia o paciente necessita ter a comunicação buconasal obturada a fim de retomar as funções de fonação, mastigação e deglutição ${ }^{5,7,13-}$ 16

Pacientes desdentados podem apresentar perda de peso e deficiências nutricionais, fatores que refletem em enfraquecimento do sistema imunológico, que é extremamente abalado durante o tratamento radioterápico $^{17,18}$. Neste sentido, inicialmente, foi solicitado que se confeccionasse um obturador palatino temporário (sem restauração estética, portanto), para que o paciente pudesse voltar a se alimentar por via oral antes de iniciar o tratamento radioterápico.

Como opções completas (estéticas e funcionais) para o vedamento de comunicações buconasais podem ser citadas a correção cirúrgica e/ou a reabilitação protética imediata ou mediata; provisória ou restauradora ${ }^{5,7,8,14,19-21}$.

As próteses obturadoras são normalmente escolhidas devido ao tempo de realização ser relativamente curto, apresentar baixo custo quando comparada à cirurgia reconstrutora e por não vedar de maneira permanente a área operada e que necessita ser observada clinicamente após a cirurgia para remoção do tumor ${ }^{21} \mathrm{e}$, portanto foram a escolha no presente caso.

Para a confecção de próteses obturadoras palatinas, a primeira etapa consiste na realização de uma moldagem de estudo, que pode ser feita com alginato, godiva ou silicone ${ }^{8}$. No caso em questão foi utilizado alginato para a moldagem de estudo devido a sua consistência, para evitar ferir a regição de comunicação buconasal do paciente, o que provavelmente ocorreria se um material mais rígido fosse utilizado.

A partir da moldagem de estudo obtém-se um modelo em gesso comum, sobre o qual, na maioria dos casos, é confeccionada uma moldeira individual para a realização de moldagem funcional ${ }^{22,23}$. Contudo, no presente caso não houve moldagem funcional do arco maxilar, solicitando-se a confecção de base de prova e plano de cera a partir do modelo de estudo. Este fato se justifica pelo estabelecido no planejamento inicial, que era o de confecção de prótese parcial removível obturadora palatina provisória. Para a confecção deste tipo de prótese a moldagem funcional é desnecessária, uma vez que, na maioria dos casos, não há preparo de nichos ou alteração de contorno, já que os grampos são confeccionados com fios de aço ${ }^{8}$. Porém, no decorrer do tratamento o planejamento precisou ser alterado, passando a ser o de uma prótese total removível obturadora palatina. Esta sim, com indicação de moldagem corretiva ${ }^{24}$.

Porém, no momento desta alteração, o caso já havia seguido até a montagem do modelo maxilar em articulador (portanto, com base de prova e rolete de cera já ajustados). Considerando-se que o limite de vestíbulo do paciente foi severamente alterado devido ao procedimento cirúrgico prévio (fato que inviabilizaria a moldagem de bordas se for considerada a técnica convencional de moldagem funcional) e também devido à necessidade de finalização rápida da prótese, optou-se por seguir o caso sem a etapa de moldagem funcional e a realização de moldagem corretiva da boca fechada em etapa posterior.

Já para o arco mandibular, foi realizada moldagem corretiva conforme preconizado pela literatura. A partir daí, foi seguida a sequência convencional para a confecção de próteses removíveis, que compreende a confecção de base de prova com rolete de cera inferior, tomada de registros intermaxilares, montagem dos modelos em articulador semiajustável, seleção de dentes artificiais e prova estética e funcional destes dentes montados em cera ${ }^{8,22,23}$

Ausência de suporte, estabilidade e retenção são problemas comuns para o paciente com comunicação em maxila. As próteses obturadoras palatinas podem ser retidas por grampos de aço ou grampos fundidos adaptados aos dentes remanescentes, quando estes podem ser mantidos; podem usar a região da comunicação para colaborar com a retenção mecânica da prótese, já que o selado periférico fica muito comprometido, prejudicando severamente a estabilidade da prótese; e, em alguns casos, podem ser retidas por implantes ${ }^{25}$. A retenção também fica prejudicada com a área a ser obturada é muito extensa, o que resulta em aumento de peso da prótese ${ }^{13}$.

No planejamento inicial, apesar da perda óssea observada na radiografia panorâmica, foi sugerida a manutenção dos dentes superiores, porém, por indicação médica e concordância do cirurgião dentista que acompanhava o paciente, os dentes foram extraídos. Esta manobra que tanto afeta a retenção e estabilidade da prótese obturadora não é rara de acontecer. Devido ao risco de osteoradionecrose, muitos profissionais indicam exodontias, ditas preventivas, em situações similares ${ }^{17,18}$. A extração dos dentes superiores interferiu negativamente na retenção e estabilização da prótese obturadora palatina.

Considerando a ausência de dentes e a impossibilidade de obtenção adequada do vedamento periférico, não restou outra opção além de explorar a retenção mecânica promovida pela própria comunicação buconasal. Assim, foi realizada moldagem corretiva, no intuito de se aumentar o bulbo obturador e corrigir a região posterior esquerda da maxila, que sofreu remoção laboratorial dos dentes. Após a moldagem, a prótese foi enviada ao laboratório para acrilização.

Porém, o procedimento de moldagem corretiva não foi suficiente, de modo que, durante a instalação, foi notada falta de retenção e estabilidade da prótese. Sabe-se que, se necessário, pode-se completar a base da prótese já acrilizada com sobremoldagem no local da perda de substância para aumentar a retenção e estabilidade ${ }^{26}$. No caso, uma semana após a instalação das próteses foi realizado reembasamento imediato com material resiliente, seguindo a mesma técnica de moldagem corretiva previamente descrita. Após o reembasamento, o ajuste das bases e oclusal foi refeito, de modo que a prótese se apresentou mais estável e retentiva, alcançando, assim, a restauração plena da fonação, função mastigatória e deglutição do paciente, que apresentou-se satisfeito com o resultado final.

\section{CONCLUSÃO}

Com base no exposto é possível concluir que é importante observar melhor as condições sistêmicas e os aspectos clínicos do paciente, bem como informar sobre a doença, para que os casos de câncer não se intensifiquem a ponto de causar perdas teciduais extremas. O diagnóstico precoce bem como o prognóstico e tratamento adequado são 
fundamentais. Se todas as etapas forem realizadas de maneira adequada, apesar das limitações impostas por este tipo de tratamento, é possível reabilitar o paciente estética e funcionalmente, trazendo satisfação ao mesmo bem como sua reinserção ao convívio social.

\section{REFERÊNCIAS}

1. Brasil. Instituto Nacional de Câncer. Estimativas da incidência e mortalidade por câncer. 2016.

2. Dedivitis RA, França CM, Mafra ACB, Guimarães FT, Guimarães AV. Características clínicoepidemiológicas no Carcinoma Espinocelular de Boca e Orofaringe. Rev Bras Otorrinolaringol. 2004; 70(1):35-40.

3. Souza LRB, Ferraz KD, Pereira NS, Martins MV. Conhecimento acerca do Câncer Bucal e atitudes frente à sua etiologia e prevenção em um grupo de horticultores de Teresina (PI). Rev bras cancerol. 2012; 58(1):31-9

4. Khan O, Protheroe A. Testis cancer. Postgrad Med J. 2007; 83(984):624-32.

5. Goiato MC, Fernandes AUR, Dos Santos DM, Barão VAR. Positioning magnets on a multiple/sectional maxillofacial prosthesis. J Contemp Dent Pract. 2007; 8(7):101-7.

6. Rolsky D, Dolegacz A, Górska R, MierzwińskaNastalska E. Multidisciplinary treatment of patients after a surgery due to cancers in the facial area: a clinical reports. Adv Med Sci. 2006; 51(Suppl 1):173-8.

7. Goiato MC, Pesqueira AA, Da Silva CR, Gennari Filho H, Dos Santos DN. Patient satisfaction with maxillofacial prosthesis. Literature review. JPRAS. 2009; 62(2)175-80.

8. Rezende JRV, Oliveira JAP, Dias RB. Prótese BucoMaxilo-Facial: conceitos básicos e praticas de laboratório. São Paulo: Sarvier; 1986.

9. Margotta V, Capogreco M. Soft tissue pathologies of the oral cavity. Minerva Stomatol. 2003; 52(1-2):47-51.

10. Carli ML, Santos SL, Pereira AAC, Hanemann JAC. Características clínicas, epidemiológicas e microscópicas do Câncer Bucal diagnosticado na Universidade Federal de Alfenas. Rev bras cancerol. 2009;55(3):205-11.

11. Nogueira AS, Pereira KMA, Turatti E, Pouchain EC, Costa FWG, Taboza ZA, et al. Perfil Epidemiológico de 23 casos de neoplasias malignas da cavidade oral atendidos em uma instituição odontológica de nível secundário. Rev bras Cir cabeça e pescoço. 2012;41(4)181-5.

12. Aguiar L, Mozzini AR, Lersch E, De Conto F. Obturador palatino: confecção de uma prótese não convencional relato de caso. RFO UPF. 2013; 18(1):125-9.

13. Campaner M, Ursi WJS. Reabilitação protética de paciente maxilectomizado [trabalho de conclusão de curso]. Londrina: Universidade Estadual de Londrina; 2014.

14. Kusterer LELF, Paraguassú GM, Da Silva VSM, Sarmento VA. Reabilitação com obturador maxilar após cirurgia oncológica: relato de casos. Rev Cir Traumatol Buco-Maxilo-Fac. 2012; 12(4):9-16.

15. Vergo TJ Jr, Andrews R. Maxillofacial prosthetics: rehabilitation of head and neck cancer patients (II). Quintessence Dent Technol. 1984; 8(6):349-56.

16. Silva DP, Almeida FCS de, Vaccarezza GF, Brandão TB, Cazal C, Caroli A, et al. Reabilitação protética de pacientes maxilectomizados: Uma contribuição da Odontologia e um convite à reflexão. Pesq Bras Odontoped Clin Integr. 2004; 4(2):125-30.

17. Grimaldi N, Sarmento V, Provedel L, De Almeida D, Da Cunha S. Conduta do cirurgião-dentista na prevenção e tratamento da osteorradionecrose:revisão de literatura. Rev bras cancerol. 2005; 51(4):319-24.

18. Vier FV, Cherubini K, De Figueiredo MAZ, Yurgel LS. Manejo da osteorradionecrose em pacientes submetidos à radioterapia de cabeça e pescoço. Rev Odonto Ciênc. 2005; 20(47):23-8.

19. Karthikeyan S, Balu K, Devaki V, Ajay R. A simple method of enhancing retention in interim hollow bulb obturator in a case of an acquired palatal defect. J Pharm Bioallied Sci. 2015; 7(Suppl 2):S782-S785.

20. Oliveira JAGP. Traumatologia Bucomaxilofacial e Reabilitação Morfofuncional. São Paulo: Santos; 2012.

21. Carvalho-Teles V, Pegoraro-Krook MI, Lauris JRP. Speech evaluation with and without palatal obturator in patients submitted to maxillectomy. J Appl Oral Sci. 2006; 14(6):421-6.

22. Paiva MC. Sequencia da confecção de uma prótese total [ monografia]. Rio de Janeiro: Clivo Odontologia; 2008.

23. Reis JMSN, Perez LEC, Nogueira SS, Ariolli Filho JN, Mollo Júnior FA. Moldagem em prótese total - uma revisão da literatura. RFO. 2007;12(1):70-4.

24. Graziani M. Prótese-Maxilo-Facial. Rio de Janeiro: Editora Cientifica; 1956.

25. Sousa AM. Retenção dos obturadores em pacientes portadores de dentes e em desdentados In: Fundação "Centro de pesquisa e oncologia". I Simpósio Latino Americano de Reabilitação da face e de prótese bucomaxilo-facial. São Paulo: Grafica Platina; 1977. p. 44-5.

26. Goiato MC, Piovezan AN, dos Santos DN, Gennari Filho $\mathrm{H}$, Assunção WG. Fatores que levam à utilização de uma prótese obturadora. Rev Odontol Araçatuba. 2006; 27(2):101-6.

\section{CONFLITO DE INTERESSES}

Os autores declaram não haver conflitos de interesse.

\section{AUTOR PARA CORRESPONDÊNCIA}

\section{Marcela Filié Hadad}

marcela.haddad@unifal-mg.edu.br
Submetido em 05/10/2016 Aceito em 25/10/2016 